\title{
The Prevalence of Skeletal Malocclusion in the Southern Aseer Region of Saudi Arabia
}

\author{
Mazen Almasri* \\ Oral Maxillofacial Surgery, Umm Alqura Uni - Makka city, Saudi Arabia \\ *Corresponding author: mazen_ajm@yahoo.com
}

Received December 27, 2013; Revised January 09, 2014; Accepted January 20, 2014

\begin{abstract}
Objective: to study the prevalence of skeletal malocclusion (SMO) cases in the orthodontic and maxillofacial surgery unit of King Khalid university health center / Aseer central Hospital (KKUHC) in the southern Aseer region of Saudi Arabia (SSA) where no previous epidemiological data took place. Materials and methods: A retrospective chart review of all the cases visiting the orthodontic / maxillofacial surgery unit at KKUHC from September 2010 to August 2012 was reviewed. All the pertinent data were extracted and tabulated for investigation while incomplete records were eliminated. Results: A total of 364 completed charts were included in the study and all the pertinent data were extracted and tabulated. It was found that $42 \%$ of the cases had skeletal malocclusion (SMO) while 58\% had dental maocclusion only. Class 3 SMO represented the majority of the cases scoring $49 \%$ of the records. The female to male ratio was 1:3.2, which is significantly lower than other recorded studies. Conclusion: SMO deformity was found to be a common presentation in the SSA health care center where class 3 comprised the majority unlike other areas in the country.
\end{abstract}

Keywords: prevalence, orthognathic, skeletal malocclusion, Saudi

Cite This Article: Mazen Almasri, "The Prevalence of Skeletal Malocclusion in the Southern Aseer Region of Saudi Arabia." American Journal of Medical Sciences and Medicine, vol. 2, no. 1 (2014): 13-15. doi: 10.12691/ajmsm-2-1-3.

\section{Introduction}

Malocclusion is an issue that can be disturbing to the patients. It can be either due to skeletal or dental relation discrepancy. The prevalence of skeletal malocclusion (SMO) varies among different population and ethnic backgrounds; nevertheless, the same cephalometric analysis norms are used for treatment planning, which might be deceiving [1]. Therefore, careful treatment planning is needed when managing facial deformities of patients from different regions around the world. The Southern Aseer region of Saudi Arabia (SSA) is a uniquely developing region where epidemiological studies have not been conducted in regard to maxillofacial deformities. As a result, most of such cases get transferred to larger cities for treatment. The aim of this study is to conduct an epidemiological pilot study pertinent to SMO and orthognathic facial deformities in the region in order to understand the actual presentation of this entity. Hence, to our knowledge, this is considered to be the first study that shed the light into this issue in the region.

\section{Material and Methods}

The completed records of patients followed at the Orthodontics / Maxillofacial division at KKUHC from September 2010 to August 2012 were collected and reviewed. A total of 364 medical charts were included of patients' age from 14-36 years old. Clinical pictures and cephalometric superimposition measurements were analyzed and the data were extracted and tabulated to verify the prevalence SMO among all the patients visiting the KKUHC.

\section{Results}

Out of the 364 files, dental-origin malocclusion was found in 210 cases (58\%) while skeletal-origin malocclusion (SMO) was found in 154 cases (42\%). Out of the 154 SMO cases, it was found that 76 (49\%) of them had class 3, of which, 26 presented with steep mandibular angle and 54 had normal mandible angle. Class 2 and class 1 comprised 39\% (60 patients) and 12\% (19 patients) of the cases respectively. (Figure 1 and Figure 2).

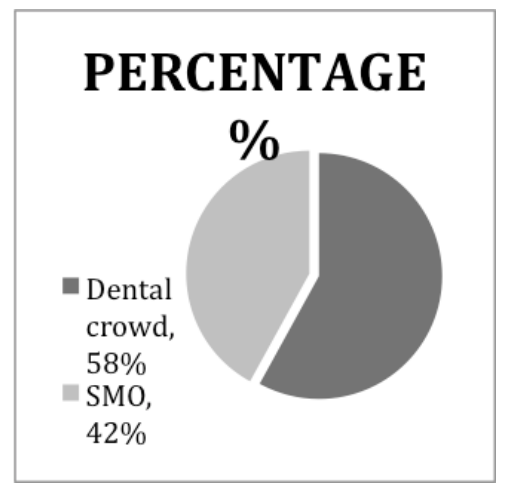

Figure 1. The prevalence of Dental crowd and SMO cases in KKUHC 


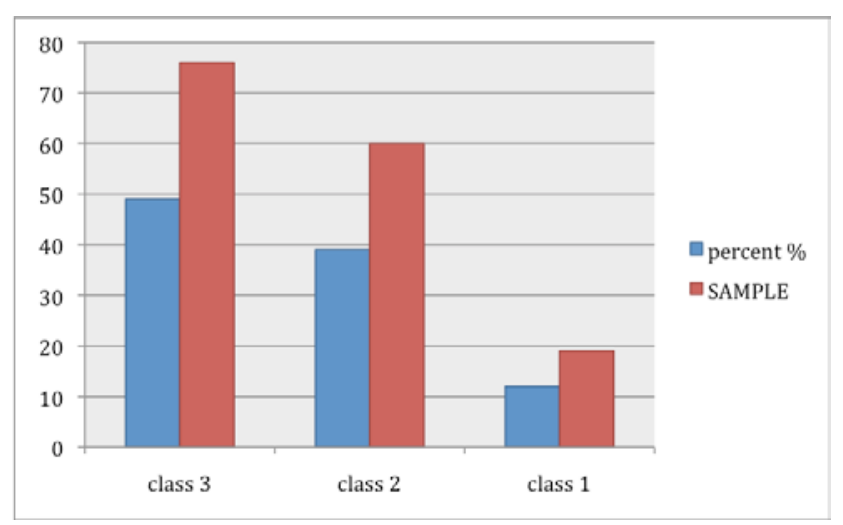

Figure 2. The prevalence of SMO subtypes

The Gender distribution showed that male patients comprised $77 \%(n=118)$ where $58 \%$ of them had class 3 SMO $(n=68)$, while female patients comprised $22 \%(n=$ 36), $50 \%$ of which were found to have class $2(n=18)$ while $38.8 \%$ had class $3(n=14)$. Further more, it was found that the SMO cases are mainly planned for referral to larger cities in the country for treatment.

\section{Discussion}

Table 1. The variable prevalence of skeletal malocclusion (SMO) in Saudi and some other different countries. ANB: A point-Nasion-B point angle, F: Female, M: Male, Wit's : Wit's orthodontic analysis of maxillo mandibular relation

\begin{tabular}{|l|l|l|l|l|l|l|l|}
\hline Study, Country & Class III \% & Class II \% & Class I \% & Study period & Age (years) & F:M ratio & Number of subjects \\
\hline $\begin{array}{l}\text { SALEH, } \\
\text { Lebanon } 1999\end{array}$ & $5 \%$ & $19 \%$ & $\% 76$ & - & $(9-15)$ & $(1: 1.15)$ & 851 \\
\hline $\begin{array}{l}\text { ONG MA, } \\
\text { Malaysia 2004 }\end{array}$ & $91.20 \%$ & $5.90 \%$ & $2.90 \%$ & 10 years & $(17-35)$ & $(1: 0.8)$ & 34 \\
\hline $\begin{array}{l}\text { AL-JASSER, } \\
\text { Saudi 2005 }\end{array}$ & $\begin{array}{l}8.14 \% \text { (ANB) } \\
35.5 \% \text { (Wit's) }\end{array}$ & 40.26 & $\begin{array}{l}\% 51.6 \text { (ANB) } \\
\% 27.24 \text { (Wit's) }\end{array}$ & - & $(20-30)$ & $(1: 1)$ & 60 \\
\hline $\begin{array}{l}\text { CHEW MT, } \\
\text { Singapore 2006 }\end{array}$ & $68 \%$ & $24.50 \%$ & $7.50 \%$ & 3 years & $(16-58)$ & $(1: 0.77)$ & 212 \\
\hline $\begin{array}{l}\text { OSHAGH ET AL, } \\
\text { Iran 2010 }\end{array}$ & $12 \%$ & $70 \%$ & $18 \%$ & - & $(6-14)$ & $(1: 0.7)$ & 700 \\
\hline $\begin{array}{l}\text { BOECK, } \\
\text { Brazil 2011 }\end{array}$ & $47.30 \%$ & $96.10 \%$ & $6.40 \%$ & 6 years & $(23-59)$ & $(1: 0.6)$ & 171 \\
\hline $\begin{array}{l}\text { ALEDRESS, } \\
\text { Saudi 2012 }\end{array}$ & $\begin{array}{l}6.8 \% \text { ANB } \\
\text { (5.6\% Wits }\end{array}$ & $\begin{array}{l}40.2 \% \text { ANB } \\
37.2 \% \text { Wits }\end{array}$ & $53 \%$ & - & $(11-48)$ & $(1: 0.9)$ & 602 \\
\hline $\begin{array}{l}\text { ALMASRI, } \\
\text { Saudi 2014 }\end{array}$ & $49 \%$ & $39 \%$ & $12 \%$ & 2 years & $(14-36)$ & $(1: 3.2)$ & 154 \\
\hline
\end{tabular}

In a neighboring country, Lebanon, Saleh FK reported that class 1 was the most prevalent skeletal discrepancy in a Lebanese sample of school children comprising 76\% [4]. It was found that $19 \%$ out of 851 schoolchildren who were included in this study were classified as class 2 SMO while only $5 \%$ as class 3 . Oshagh $\mathrm{M}$ et al., presented the results in Iran (Shiraz university health center), where class 2 SMO was found to be more prevalent representing $70 \%$ of the cases [5].

In the far eastern part of Asia, several studies concerning the prevalence of SMO had been conducted. It was found that class 3 was the most prevalent type $[6,7,8]$. Interestingly, the results are almost the same in South America, Brazil, where class 3 SMO considered being more dominant $[9,10]$.

The female to male ratio in our study was 1:3.2, which contradicts most of the other studies $[6,7,9]$. This result might not represent the actual score due to the
The Southren Aseer region of Saudi Arabia is a region of significant development in education and health care. However, management of some subspecialized medical conditions such as maxillofacial deformities are still emerging. The aim of this study is to investigate the prevalence of SMO among patients visiting the orthodontics / oral maxillofacial surgery unit in KKUHC and to study if that incidence differs from other population in the Kingdom of Saudi Arabia and other countries. Our study showed that $42 \%$ of the patients visiting the KKUHC have SMO (orthognathic deformity), of which, most found to be males with class 3 skeletal malocclusion that differ from other studies in Saudi.

In the middle region of Saudi, Riydh city, Alidress et al analyzed the records of 602 pretreatment orthodontics cases of patients with a mean age of 16 attending the orthodontics clinics at King Saud University [1]. It was found that the majority (51.7\%) had class 1 SMO, while $40.2 \%$ were classified as having class 2 SMO. This is in accordance with other epidemiological studies took place in Riyadh [2,3]. Jones WB reported that class 1 SMO to be the dominant feature among cases seen at the Riyadh armed forces hospital in Saudi Arabia counting for 46.4\% [2]. (Table 1). conservative cultural background that dictates more of a homebound female lifestyle. Hence, it is expected that the ratio will change if a larger scale epidemiology study took place in the region. The former suggests that SMO has a different presentation in variable areas around the world, which dictates the need of special consideration in managing such abnormalities as the perception of "normal facial proportion” can differ accordingly [11].

\section{Conclusion}

This epidemiplogy pilot study is the first of which investigating the skeletal malocclusion in the Southern Aseer region of Saudi. It showed a higher incidince of class three SMO than other regions in Saudi which had class one and two to be more dominant. Such variablities suggest careful considerations while planning for 
maxillofacial surgeries as well as in using Caucasain lateral cephalometric norms for Saudis.

\section{Conflict of Interest}

The author declares that no conflict of interest existed.

\section{Acknowledgement}

The Author would like to thank the Maxillofacial research center in the Faculty of dentistry of King Khalid University, for facilitating the work. As well as a special gratitude to Dr Fawaz Baig (Oral maxillofacial surgery dept - King Khalid University) and Dr Sara Bukhari (King Abdulaziz Medical City) for their help and support.

\section{References}

[1] Aldrees A., "Pattern of skeletal and dental malocclusions in Saudi orthodontic patients”. Saudi Med J. 33 (3): 315-20. 2012.

[2] Jones W., "Malocclusion and facial types in a group of Saudi Arabian patients referred for orthodontic treatment: a preliminary study”. Br J Orthod. 14: 143-146. 1987.
[3] Al-Jasser N., "Cephalometric Evaluation for Saudi Population Using the Downs and Steine Analysise”. J Contemp Dent Pract. (6) 2: 052-063. 2005.

[4] Saleh FK., "Prevalence of malocclusion in a sample of Lebanese schoolchildren: an epidemiological study”. East Mediterr Health J. 5 (2): 337-43. 1999.

[5] Oshagh M., Ghaderi A., Pakshir A., Baghmolla, "Prevalence of malocclusions in school-age children attending the orthodontics department of Shiraz University of Medical Sciences”, Eastern Mediterranean Health Journal. 16: 12-14. 2010.

[6] Ong M., "Spectrum of dentofacial deformities: a retrospective survey”. Ann Acad Med Singapore. 33 (2): 239-42. 2004.

[7] Chew M., "Spectrum and management of dentofacial deformities in a multiethnic Asian population”. Angle Orthod. 76 (5): 806-9. 2006.

[8] Samman N., Tong A., Cheung D., Tideman H., “Analysis of 300 dentofacial deformities in Hong Kong”. Int J Adult Orthodon Orthognath Surg. 7 (3): 181-5. 1992.

[9] Boeck E., Lunardi N., Pinto Ados S., Pizzol K., Boeck Neto R., "Occurrence of skeletal malocclusions in Brazilian patients with dentofacial deformities”. Braz Dent J. 22 (4): 340-5. 2011.

[10] Boeck E., Gimenez C., Coleta K., "Prevalence of skeletal malocclusion's types analysed in patients with dentofacial deformities”. R Dental Press Ortodon Ortop Facial, 8: 73-78. 2003.

[11] Almasri M., Bukhari S., "considerations to planning orthognathic surgery in different regions of Saudi and the middle east”. Am J of public Health and Research, 2 (1): 6-9. 2014. 